\title{
Los discursos públicos y los testimonios y registros de la vida privada de Ernesto Guevara en Che... Ernesto y Che un hombre nuevo.
}

\author{
Jimena Cecilia Trombetta*
}

\begin{abstract}
Resumo: Nos filmes Che ... Ernesto (1997), de Miguel Pereira e Che, un hombre nuevo (2010), de Tristan Bauer podemos encontrar linhas criativas para a compreensão do pensamento de Ernesto Guevara e outras que apontam para reprodução de imagens míticas ancorados em uma tradição da representação de Che. Como os discursos de conhecimento público são utilizados e como os documentos da esfera privada são introduzidos?

Palavras-chave: documentary; memória; história; mito; Che Guevara.
\end{abstract}

Resumen: En Che... Ernesto (1997), de Miguel Pereira y Che un hombre nuevo (2010), de Tristán Bauer se pueden hallar líneas creativas que van hacia la intención de comprender el pensamiento de Ernesto Guevara y otras que apuntan a reproducir imágenes míticas ancladas en una tradición de representación sobre su figura. ¿Cómo se utilizan los discursos de conocimiento público y cómo se introducen los documentos del ámbito de lo privado?

Palabras clave: documental; memoria; historia; mito; Che Guevara.

Abstract: In Che ... Ernesto (1997) by Miguel Pereira and Che un hombre Nuevo (2010) by Tristán Bauer one may find creative lines that go towards the understanding of the though of Ernesto Guevara and others that reproduce mythical images anchored in a tradition of representation on his figure. How are the public knowledge discourses used and how do private sector documents are introduced?

Keywords: documentary; memory; history; myth; Che Guevara.

Résumé: Dans Che ... Ernesto (1997), de Miguel Pereira et Che un hombre nuevo (2010), de Tristan Bauer, on peut trouver des lignes créatives qui vont de l'intention de comprendre la pensée d'Ernesto Guevara à d'autres qui reproduisent des images mythiques ancrées dans une tradition de représentation de cette figure. Comment les discours de la connaissance du public sont utilisés et comment les documents issus de la sphère privée y sont introduits ?

Mots-clés: documentaire; mémoire; histoire; mythe; Che Guevara.

* Universidad de Buenos Aires, Facultad de Filosofía y Letras, Instituto de Artes del Espectáculo. 1431, Buenos Aires, Argentina. E-mail: jimenacecilia83@gmail.com

Sumisión del artículo: 16 de deciembre de 2016. Notificación de aceptación: 30 de enero de 2017.

Doc On-line, n. 21, março de 2017, www.doc.ubi.pt, pp. 133-146. 


\section{Introducción}

La imagen de Ernesto Guevara de la Serna fue santificada, demonizada y ubicada por el capitalismo en el estatus de producto para ser comercializado a través de una serie de objetos de merchandising, tal como sostiene Germán Sánchez (1989). Así en Argentina en los años noventa por medio de la cinematografía se intentó recobrar la imagen política del Che y llenar de sentido eso que estaba siendo vaciado. Sin embargo, gran parte de los documentales cayeron en reproducir la imagen de héroe guerrillero tal como ya se había planteado por otros agentes. De este modo, la metamorfosis médico-guerrillero-ministroguerrillero, también aplicada en los documentales sobre el guerrillero heroico, siguió mitificando su figura. La manera de mitificarlo fue utilizar sus discursos políticos y los testimonios como elementos que re-direccionaban esa mutación. Lógicamente la cinematografía lo lograba a través de mecanismos formales como el montaje y la selección o el recorte de realidad que proponía. La intención de este artículo es analizar un corpus limitado de films, Che... Ernesto (1997) de Miguel Pereira y Che un hombre nuevo ${ }^{1}$ (2010) de Tristán Bauer. Dentro de estos documentales, que podríamos pensarlos como 'documentales de memoria' (Gauthier, 1995), analizaremos cómo se representan los modos de enunciar y pronunciar los discursos políticos y su interacción con distintos sectores sociales, en tanto que creemos que en cada creación se pueden hallar líneas que van hacia la intención de comprender el pensamiento de Guevara y otras que apuntan a reproducir imágenes míticas ancladas en una tradición de representación sobre su figura como Cristo, Robin Hood, Don Quijote o Giuseppe Garibaldi.

Para dicha empresa tendremos en consideración cómo se utilizan los discursos de conocimiento público y cómo se introducen los documentos del ámbito de lo privado. Este análisis observa que los documentales buscan humanizar al Che analizando su pensamiento, marcan una tendencia que lo ubica en el terreno de leyenda, o incluso, combinan estos dos resultados, siempre a partir de la reapropiación de los creadores sobre los testimonios, documentos y discursos. Carlos Tablada Pérez (1987), al analizar el pensamiento económico del comandante señalaba que muchos trabajos caían en ubicar la figura de Ernesto Guevara en el espacio de lo extraordinario, dónde su pensamiento se reducía a una postura idealista y voluntarista, mientras que este autor desde su trabajo expone los puntos científicos del pensamiento ideológico de Guevara con su perfil marxista-leninista que lo deja por fuera de la mera leyenda. En

1. El documental fue producido para conmemorar el ${ }^{\circ} 40$ aniversario de la muerte de Guevara. Se pasó por Canal Encuentro, canal perteneciente al estado argentino. Fue distribuida en España por Golem. Fue una co-producción de Cuba, Argentina y España. Se estrenó el 29 de octubre de 2010. 
esa misma lógica se refiere a la idea de hombre nuevo. Desde esta perspectiva juiciosa queremos observar si dentro de los documentales a trabajar predomina el concepto de hombre nuevo (es decir aquel hombre revolucionario capaz de comprender conscientemente los procesos sociales y actuar en consecuencia) o una postura que lo idealiza como líder. Existe una diferencia entonces entre un Che ubicado en el lugar de una figura con poder sobre el pueblo, y uno ubicado en el lugar de una figura que busca otorgarle poder consciente y real al pueblo.

En este punto queremos verificar si los materiales del mundo de lo privado de Guevara vienen a constatar esta posición política o si al ser utilizados estos materiales dentro del terreno de un montaje y una mirada específica se tornan elementos públicos para contribuir aún más a la posición mítica de héroe popular, más que a la comprensión de una personalidad política con un análisis político en un contexto histórico específico. A su vez vamos a desarrollar como la utilización de los discursos públicos y el registro del pensamiento político dentro de los documentales de Tristán Bauer y Miguel Pereira apuntan a conformar la imagen del Che como héroe guerrillero. A partir de allí demostraremos que los registros de la vida cotidiana en el documental datado en 1997 propician una imagen extraordinaria de la figura de Guevara, mientras que el trabajo de Tristán Bauer lo matiza humanizando su figura a través de la inclusión de diversas aristas de la personalidad. A su vez consideraremos que, en el primer documental, aun queriendo revisar la historia, mitifica a la figura heroica de un modo rígido, mientras que en el otro caso, en términos de Pedro Geltman (1969), el mito que genera no es esclerotizante sino dinámico, en tanto que lo demoníaco o santificado es disminuido. A su vez, si contestamos momentáneamente que los documentales sobre el Che en mayor o menor medida propician un mito, nos interesa preguntarnos entonces si esto es en base al modo de utilizar los documentos, la historia, o si esto surge aún más por la constitución de ellos como documentales que recurren a testimonios y a la constitución de una memoria sobre la figura. Para comprender cómo se articulan los archivos y testimonios en dichos documentales tendremos en cuenta las relaciones que se establecen entre la memoria y el contenido de 'lo real' dentro de los films considerando las posiciones teóricas de Sylvie Lindeperg (2009), Ana Amado (2009), Vivian Sobchack (2011), y María Belén Ciancio (2015). A su vez hay que señalar que pensando desde la perspectiva barthesiana donde todo acto de habla es mito, los testimonios utilizados en los documentales no dejarán tampoco de ser constructores de mitos. En este punto, nos parece pertinente considerar y aplicar las categorizaciones que expone Gustavo Aprea (2015) sobre testimonio tanto como también sus con- 
sideraciones sobre los documentales de memoria, concepto que extrae de Guy Gauthier (1995) y que luego aplica a la producción cinematográfica de Argentina. A su vez nos interesa ver cómo estos documentales se posicionan frente a un contexto posmoderno.

Con el objetivo de cubrir lo aquí planteado partiremos de dos apartados basados en dos preguntas específicas ¿Qué de lo público toman los documentales y cómo configuran desde allí la imagen de Ernesto Guevara? y ¿Qué de lo privado introducen los documentales y cómo conforman desde allí la imagen del comandante? En el primer apartado nos preguntaremos sobre ¿cómo se utilizan los archivos públicos? En el segundo apartado problematizaremos cómo funciona el concepto de memoria en estos documentales, cómo trabajan los testimonios y cómo trabajan con los archivos de índole de lo privado.

\section{¿Qué de lo público toman los documentales y cómo configuran desde allí la imagen del Che?}

Eric Hobsbawn (2011) realiza un análisis sobre como las ideas marxianas fueron releídas y aplicadas en los gobiernos socialistas a lo largo de la historia. Dentro del análisis establece una distinción sobre cómo fueron aplicadas por el propio gobierno cubano, dentro del cuál una de las figuras más representativas fue el propio Ernesto Guevara. A su vez explica como los países socialistas formularon el marxismo y en su raíz encuentra una gran diferencia con la teoría marxiana en donde los países marxistas como Cuba concentraron su revolución no en la clase obrera si no en la clase campesina. Esto vendría posteriormente a generar cierto ruido en los resultados de las intentonas revolucionarias en el resto de los focos guerrilleros. Hobsbawn explica que este tipo de situaciones se dan porque "Desde el momento en que cualquier conjunto de ideas sobrevive a su creador, cesa de estar confinado a sus intenciones y contenidos originales" (2011: 350). Desde esta postura es que nos preguntamos ¿Cómo se utilizan los archivos en las prácticas documentales?

Creemos que los documentales se encuentran en un contexto histórico específico en el que se preguntan por el ejercicio de la memoria.

La proliferación de discursos sobre la memoria en la primera década del nuevo milenio tuvo como consecuencia lo que las ciencias sociales llaman un exceso o "hipermemoria". Como describen Daniel Lvovitch y Jacquelina Bisquert, "por parte de algunos voceros del movimiento por los derechos humanos, la memoria ha devenido 'hipermemoria', mito, convirtiendo a las víctimas en héroes revolucionarios". (Lanza, 2016: 5).

Esto los hace conformar un modo particular de manejar los archivos y los testimonios. 
Por este motivo, nos interesa observar que el documental de Miguel Pereira muestra muy poca cantidad de archivos en relación al material exhibido por Tristán Bauer. Si bien ambos documentales hablan del guerrillero heroico, el trabajo de Pereira concentra su línea argumental en narrar y mostrar el viaje que realizan Envar el Kadri y Gerardo Klein con la finalidad de recorrer los mismos sitios por dónde pasó Guevara en sus viajes por Latinoamérica. A partir de allí el documental reconstruye el viaje que llegó a convertirlo en héroe guerrillero. Luego el documental de Tristán Bauer en un ejercicio de mayor reflexión narra las inquietudes del propio documentalista por conocer la historia de vida, así se muestra al creador del trabajo en escena visitando determinados archivos. Desde allí y desde la vinculación con la familia Guevara de la Serna reconstruye la niñez, la adolescencia y su desempeño como guerrillero y como político.

En el caso de Pereira los archivos consultados son algunas pocas fotografías y el acta de casamiento, siempre mediados por el relato del protagonista del documental Envar El Kadri que narra como si estuviese recordando la vida del Che y sus viajes por Latinoamérica. Por su parte Bauer ofrece un listado completo de instituciones con archivos sobre la vida del héroe, y a ello se suma una postura objetivizante sobre los hechos. Asimismo, creemos que ambos documentales lo ubican en el rol de héroe guerrillero. Sin embargo, el trabajo de Bauer no lo limita a ese espacio, algo que el trabajo de Pereira por las características afectivas del narrador (El Kadri) y por la incorporación de algunos testimonios de los pobladores de los países por los que transitó Guevara, lo ubican de lleno en ese lugar. Palabras de admiración, expresiones afectivas y narraciones épicas serán algunos de los elementos que alimentan esa construcción mítica. Otra diferencia entre los dos documentales es que el primero construye el pensamiento político desde la concepción política de Envar El Kadri (y su joven interlocutor, Gerardo Klein); mientras que el segundo documental conforma el pensamiento político desde los planos sobre los archivos originales. De estos archivos Bauer lógicamente establece un recorte, pero se pueden apreciar frases sobre la unidad americana desde la propia voz o escritura de Ernesto Guevara. En este punto sostenemos que ambos documentales mitifican al comandante. El primero cristaliza su figura como si fuese una estampa. El segundo -si bien lo mitifica por construirlo desde las características del dispositivo cinematográfico- brinda una construcción dinámica de la figura heroica en tanto que propone diversas aristas de su personalidad: el Che guerrillero, el escritor, el pensador, el político, etc.; y no solo la metamorfosis señalada médico-guerrillero-ministro-guerrillero. En este punto, el documental de Bauer incorpora archivos de Guevara dando discursos en la ONU en 
contra de las políticas de Estados Unidos, a su vez se lo ve siendo entrevistado por Jorge Masetti ${ }^{2}$ en la que destaca la idea de que América es una sola tal como lo sostenía: el paladín de la unidad José Martí. Es notable ver como el documental de Bauer ubica sus discursos públicos quitando el resultado histórico de esos discursos. La idea de unidad latinoamericana que propone el Che que se traslada al intento de la guerrilla de Masetti no baraja el error táctico de concebir a la clase campesina argentina similar a la clase campesina cubana. En este punto la idea de unidad americana es al menos cuestionable en el ámbito de lo bélico.

Ana Amado sostiene que:

El testimonio, como género discursivo, da cuenta de un yo que desplaza su subjetividad al mundo. Mirada individual, encuadre específico: interpretación por la que las acciones privadas se expresan desde la conciencia del marco público donde se inscriben. Sostenida por un cuerpo (una rúbrica), la palabra testimonial se tiende como un puente hacia el universo de signos que la realidad -en términos de cultura, de comunidad- le alcanza. (2009: 127).

En este sentido, el trabajo de Pereira recurre a dejar en la voz del protagonista esas anécdotas que "contextualizan" la escena política que vivió el comandante. Por ejemplo, en la charla que tienen en Guatemala con Ana, una mujer militante de la época de El Kadri, narra la situación de Guevara en Guatemala y su relación con Arbenz y su derrocamiento en $1954^{3}$. Sin embargo, aquí existe un desfaje histórico en tanto que en ese contexto de Guatemala descripto por el documental (apuntan sobre el año 1960 y no 1954) el comandante aún no era el Che, si no que aún era Ernesto Guevara, pareja de Hilda Gadea. En este caso Che... Ernesto... si buscaba situar la figura en el rol de héroe guerrillero, sin ir más lejos el documental finaliza con una concatenación de fotografías que marcan la metamorfosis de Ernestito al Che. Otros ejemplos de índole pública es cómo el pensamiento político sobre la unidad americana es apropiado por el protagonista, y cómo se explica que el futuro comandante elabora dicho pensamiento a lo largo de su viaje por América.

2. Recordemos que Jorge Masetti luego de entrevistar a Guevara mantuvo frecuentes diálogos hasta conformar el Ejército Guerrillero del Pueblo (EGP) en 1964 y pasó a ser el Comandante Segundo. Frente a la asunción del Doctor Illia al gobierno argentino Masetti da primero la orden de posponer los planes guerrilleros, para luego de avisar que se siga con la comitiva. Sin embargo, ninguna revolución habría en Argentina, los focos guerrilleros estaban mal ubicados, puesto que la clase campesina no funcionaba políticamente (O’ Donnell, 2012). Así Masetti terminaría desaparecido en Salta.

3. En 1954 se encontraba en Guatemala con Jacobo Arbenz como presidente. En ese período el gobierno de Arbenz estaba siendo atacado por Castillo Armas y la CIA. Ernesto que estaba en pareja con Hilda Gadea fue asilado por la embajada a pesar de no tener un vínculo con el gobierno de izquierda, en tanto que Gadea había sido presa por haber estado vinculada con el gobierno depuesto (O' Donnell, 2012). 
Tristán Bauer establece con la incorporación de otras imágenes históricas que remiten al contexto del comandante, los motivos de las acciones de Guevara. De este modo, Bauer recuerda en el comienzo del documental, mediante la concatenación de imágenes, el asesinato a Patrice Lumumba, el ataque a Vietnam, y las actuales guerras en Medio Oriente. Así Bauer recurre a archivos fílmicos que se extienden desde el empleo de imágenes como los de La hora de los hornos (Fernando Solanas- Octavio Gettino, 1966-1968), Hanoi Martes 13 (Santiago Álvarez, 1968), Abril de Vietnam (Santiago Álvarez, 1975), Historias de la revolución (Tomás Gutierrez Alea, 1960), Tierra seca (Oscar Kantor, 1962), Hasta la victoria siempre (Santiago Álvarez, 1967), Historia en África (Rebeca Chávez, 1997); hasta la utilización de imágenes de noticieros como el de ICAIC, Noticuba, la BBC, AlJazeera y el Canal 7 de Argentina, entre otros materiales utilizados. En este caso todos estos films combinados y montados por el cineasta conforman un corpus que legitima los discursos dictados por el Che, por ejemplo, el mencionado en la ONU. Así Bauer sostiene la ideología de Guevara dándole legitimidad política y contextualizando sus acciones históricamente, más allá de que su pensamiento haya sido fallido en la práctica.

En este punto el documental intenta combatir el vaciamiento histórico sobre la figura. En este sentido, consideramos las ideas de Sylvie Lindeperg (2009) sobre la incorporación de los archivos. Lindeperg estudia el caso de cómo se trabajaron las imágenes de archivo en Noche y niebla (1955) de Alain Resnais. Lo interesante es retomar el planteo de esta autora sobre cómo el film se pregunta sobre las imágenes y cómo lo hace la mirada de hoy. A su vez anota que los archivos están expuestos bajo dos miradas yuxtapuestas de la época: "la mirada de los verdugos y la mirada de los testigos" (2009: 63). Más adelante estudia la diferencia entre como los cineastas fueron evaluando la posición ética entre mostrar o no mostrar el archivo, de dónde proviene el mismo y cómo nos posicionamos frente a la mirada de quien la tomó. En este punto desarrolla una diferencia entre la imagen ausente, es decir aquella que por una mirada ética no podemos mostrar; y aquellas faltantes, esas imágenes que debemos encontrar para dar cuenta de lo real del acontecimiento. (Lindeperg, 2009). Así, tanto el pensamiento que se expresa dentro del documental de Bauer, como las narraciones de Envar El Kadri en Che... Ernesto sobre la mirada política de Guevara y sus discursos políticos buscan afianzar la figura en el pasado para pensarla en un presente. El Kadri en el documental es voz autorizada por su propia participación en la militancia dentro de las columnas del peronismo y por su intento de promover los movimientos de insurgencia 
campesina en Tucumán en el campamento de Taco Ralo ${ }^{4}$ en 1968, de la mano de las FAP. Así su propia acción política lo habilita a hablar de la acción política del comandante.

\section{¿Qué de lo privado introducen los documentales y cómo conforman desde allí la imagen del Che?}

Como bien señala Gustavo Aprea (2015) los documentales en los años '90 comienzan a constituir las figuras que quieren narrar agregándoles detalles de la cotidianeidad, temores y flaquezas. En el documental de Pereira ${ }^{5}$, parafraseando a Aprea, la puesta se construye como un acto recordatorio legitimado desde la visión del pasado del protagonista. Envar el Kadri construye el mundo público tal como vimos, pero también desde su propio interior pretende comprender e imaginar el interior de su coetáneo. Así "el ser privado se trasviste en ser social" (Amado, 2009: 128) En esta dinámica, el documental sin recurrir a un solo archivo privado, más que la constancia de casamiento con Hilda Gadea, construye el interior de acuerdo a lo que hubiese sentido en sus viajes. En un salto radical, el trabajo de Bauer construye el mundo privado de Guevara acudiendo a la investigación y a la exposición de esos resultados. Así, Bauer construye la memoria sobre el Che, desde la propia voz y escritura de él. Lo cotidiano con Aleida se muestra en diversas fotografías, en los poemas grabados tanto el de César Vallejo "Los Heraldos Negros", como "Farewell y los sollozos" en Crepusculario de Pablo Neruda, en la carta a sus hijos, a sus padres. Todo esto acompañado por el plano detalle sobre el archivo o la voz de un narrador en off, que varía entre Bauer y Rafael Guevara. Puntualmente nos interesa destacar como Bauer combina ese mundo cotidiano y privado con el mundo de lo público. El documentalista se debate sobre estas diferentes miradas que observamos más arriba que señala Lindeperg (2009). Las imágenes de la guerra en Vietnam y las bombas atómicas en Hiroshima y Nagasaki se combinan con la lectura de los poemas por Ernesto Guevara. En esa grabación

4. En el siguiente link, Envar El Kadri testimonia sobre Taco Ralo www.youtube.com/ watch? $\mathrm{v}=\mathrm{Q}$ oO06-i6T34.

5. Este documental fue auspiciado por la Secretaría de Cultura de la Nación en 1997. En el mismo agradecen a Mario Pacho O' Donnell, quien había sido secretario de Cultura de la Nación hasta abril de 1997, momento en que decidió presentar su renuncia luego de haber asumido el 21 de septiembre de 1994.Miguel Pereira declaraba cómo se habían generado la creación de la película: -Para esta película me llamó Pacho O’Donnell cuando era ministro de Cultura. La idea fue de Fernando Sokolowicz, quien también produjo la película sobre la vida del héroe guerrillero, que dirigió Desanzo, y quería que yo hiciera un documental. Para esto me dio carta blanca. Empecé a repasar todo lo que hay sobre el Che, que es enorme. Cuando terminé pensé que el material era aburrido. No sabía si por su total falta de objetividad. (...) se las arreglaban para hacer propaganda. De cualquier manera, había otro hecho que estaba claro en esos filmes. A pesar de la deliberada exaltación, la auténtica fuerza que hay en el Che sobrevivía. www.pagina12.com.ar/1999/99-01/99-01-04/pag12.htm 
él comienza con una declaración sumamente personal: "Esto es lo único íntimamente mío e íntimamente de los dos que puedo dejarte ahora”, le dejará grabado a su esposa antes de viajar a sus próximos destinos. A esa lectura se le suma una carta a Aleida en la que el Che evoca Hiroshima y su saldo de 180.000 muertos a causa de las bombas ejecutadas por los Estados Unidos.

Entonces mientras que el documental de Pereira posiciona los testimonios evocando la figura de Guevara, Bauer evoca la figura desde la propia subjetividad del Che y la incorporación de los archivos que decide combinar y mostrar. En el trabajo de Bauer ${ }^{6}$ él se posiciona como quien historiza y testimonia sobre su investigación. Asimismo, no existen testimonios de un tercero directo, si no que la utilización de los diarios, las cartas y las grabaciones conforman un producto construido a partir del ejercicio de la memoria. Escribir un diario es ejercer la memoria, tanto como escribir una carta o hablar sobre hechos pasados en una grabación. En este sentido, no es un documental de memoria estrictamente como lo denomina Aprea, si no que a partir de la utilización de los archivos construye ese recinto memorial proveniente de los registros históricos. Alejandro Cattaruzza sostiene que,

(...) la utilización de representaciones del pasado exhibe características propias. La primera de ellas es que siempre se trata de una competencia y un debate entre varias lecturas de la historia. La segunda, que esos debates tienen un objeto declamado, y ciertamente auténtico, constituido por las imágenes del pasado, y otro implícito, tan auténtico como el anterior, que se define en el presente y está asociado a los conflictos político-sociales del momento. (Cattaruzza, 2007: 19).

La pregunta inmediata es cuestionar porqué ese recinto de memoria no sería desde nuestro punto de vista netamente histórico puesto que trabaja con archivos y documentos precisos. Creemos que esos archivos son utilizados de acuerdo a una construcción que descansa en el punto de vista no sólo de Bauer sino también de la memoria de Ernesto Guevara (en sus diarios) y su hermano (con el tono de voz que le agregará a lo narrado); y también descansa la construcción del mundo de lo privado en los registros fílmicos de la familia del Che en los que se lo ve jugar y veranear con sus congéneres. Nuevamente ese material privado es transformado por la narrativa del documental en registros históricos que justifican el posterior desempeño como héroe guerrillero: porque tuvo asma de niño se enfrentó con la muerte, razonamiento propuesto en el documental. Pero además la interpretación de esos archivos descansan

6. Hay que recordar que Bauer en el documental aparece como uno de sus personajes. En tanto que se lo ve en distintos planos visitando los archivos de Bolivia guardados en el Archivo Militar. En este punto Bauer se sitúa como investigador enumerando los 29 volúmenes sobre la historia secreta y clasificada guerrillera del Che en los montes bolivianos; también menciona los 3 cuadernos inéditos y se pregunta por los legados que dejó Guevara. 
en la recepción. Vivian Sobchack (2011) destaca como desde un estudio sobre la identificación cinematográfica se "devuelve "la carga de lo real"a la experiencia fílmica" (15), es decir que "el espectador es un agente activo en la constitución de lo que cuenta como memoria, ficción o documento." (2011: 16) Este tipo de fenómeno desde ya sucede en ambos documentales pero queremos remarcarlo en el de Bauer por ser el que más utiliza los archivos.

En el caso del documental de Pereira, el afecto y la evocación se desliza desde el montaje y la dirección, como mencionamos, hacia la narrativa que propone Envar El Kadri como figura que compartió el contexto político que vivió el comandante. De este modo el personaje de El Kadri en el documental se posiciona como el primer testigo sobre la figura para sumar otros testigos azarosos (hombres y mujeres de los pueblos y ciudades por los que pasó) que solo irán a reproducir la imagen del héroe guerrillero, la del hombre extraordinario e incluso la imagen del Che-santo. En este punto el documental solo termina testeando la inmovilidad de la figura con algunas pocas escenas que la dinamizan. Entre los ejemplos que retoman el mundo privado se encuentra el registro de la libreta de casamiento de Ernesto Guevara de la Serna con Aleida March, escena en la que prima la misma dinámica entre El Kadri y Klein: el primero enseña los elementos a su discípulo. La contemporaneidad generacional de El Kadri con Guevara parece habilitarle no sólo la comprensión política sino también el acceso al mundo afectivo de la vida cotidiana del Che. En este film a diferencia del de Bauer, la figura es conformada como un héroe con poder popular que hizo mecha en las poblaciones en las que pasó, de tal modo lo refiere el recorrido que plantea el documental de Pereira. A las explicaciones del protagonista como mencionamos se le suman los discursos de los pobladores. Por el contrario, Bauer con el manejo de los archivos provoca una mayor dinámica sobre la figura del Che al otorgarle mayor peso político, y al enfocarlo como un hombre que buscó darle poder a los pueblos. Un punto más dinámico (Geltman, 1969) para poder repensarlo como figura en el devenir del presente.

María Belén Ciancio que retoma a Deleuze observa que los pueblos no podían ser representados después de las guerras mundiales y las masacres de los diferentes regímenes totalitarios, con excepción de los pueblos tercermundistas. Para Deleuze, señala Ciancio los pueblos estaban en un constante devenir donde esta constante crisis generaba una "actualización de la memoria" (2015: 87). Existe entonces: "una memoria lineal que se encadena entre imágenes sensoriomotrices y una memoria laberíntica que no cesa de bifurcarse entre presentes y pasado que no distinguirían entre lo imaginario y lo real" (Ciancio, 2015: 89). 
De todos modos, tanto bajo la mirada de Bauer como la mirada de Pereira "Lo que queda es la mirada de proximidad teñida de afecto, la mirada remota (Lévi-Strauss) que tiene por objeto reunir los fragmentos de una realidad huidiza, dicho de otra manera, comprender. El cineasta inventa lo que filma, después corta." (Gauthier, 1995, 232; cita aplicada en Aprea, 2015: 93). En este punto si ambos cineastas inventan al montar los testimonios y archivos privados, inventan mitos: nuevas lecturas sígnicas sobre signos previos (Barthes, 2004). Existe una diferencia entre ese proceso mítico sobre los archivos privados en relación a lo público. En este caso, el documental posibilita una posición pública sobre los archivos privados, pero los extirpa de su tiempo real y los vincula directamente con el afecto del cineasta. El cineasta, fundamentalmente Bauer (recordemos que Pereira casi no utiliza recuerdos privados de Guevara en su documental), publica su propio ordenamiento sobre lo privado con la intención de que eso que publica mantenga la ilusión de privacidad, para que en este caso y desde nuestro punto de vista esa privacidad sea leída como la llave que sostiene los archivos públicos, sostiene el perfil ideológico y político sin ninguna fisura en su imagen. En este sentido, en términos de Geltman (1969), lo que podría verse como dinámico del documental, es decir la intencionalidad de revisitar históricamente la figura, el tipo de relato hace que aquella regrese al mármol.

\section{Conclusiones}

La imagen de Ernesto Guevara en el posmodernismo fue vaciada de sentido por el mercado, por las ventas de productos con su imagen más pregnante, al punto que esa misma fotografía sacada por Alberto Korda también fue desarticulada de su contexto. Frente a este vaciamiento histórico, que en este artículo no vamos a evaluar si fue planificado o no (eso requeriría un mayor análisis), los documentales funcionaron como una revancha a ese vacío. Así pudimos observar uno de los documentales que surgió a partir del descubrimiento de sus restos que fue filmado en medio de la época donde la concepción de la muerte de la historia aún estaba en boga. Y también en contraposición observamos un documental estrenado en pleno revisionismo histórico y cercano al aniversario de las gestas independentistas, pero que había comenzado a pensarse en los noventa.

Lógicamente, más allá de esta postura de los documentales que busca combatir la falta sobre la imagen, los mismos se realizaron en momentos históricos diferentes. El de Pereira dejaba entrever el fracaso de la generación del setenta en palabras de Envar El Kadri, en cambio el documental de Bauer, finalmente estrenado en 2010, se formulaba como un balance de los discursos políticos 
de Guevara, reformulaba la memoria sobre el comandante y analizaba por qué sus acciones políticas fueron justificadas en el contexto histórico en el que se produjeron según su interpretación.

En este punto abordaron de modo diferente como pudimos ver los discursos políticos. El documental del año '97 exponía su punto de vista a través del pensamiento de su principal personaje; el segundo lo dejaba en ocasiones en boca del propio héroe guerrillero para resignificar esos discursos desde el montaje propuesto. Del mismo modo eran trabajados los archivos públicos y privados, mientras que en el primer documental la búsqueda era mediar todos los archivos con el personaje principal, con su propia interpretación sobre los mismos, en el siguiente caso los archivos eran entrelazados con la finalidad de dar un justificativo causal y racional que imprimiera sin mediaciones la figura de Guevara.

Mientras que el documental de Pereira incorporaba testimonios de los pobladores y alimentaba el costado mítico más esclerotizante sobre la figura, el documental de Bauer intentaba alimentar la constitución de la figura desde sus propios escritos, sus propios testimonios. Claro que sin tener en cuenta que en la acción volcada de Ernesto también existía una reconstrucción y una descripción interpretada sobre los hechos, que conformaba todo un sistema de memoria alrededor de él.

En suma, consideramos que en ambos casos, más allá de si dejan la figura del Che en un espacio inerte o intentan nutrirla con nuevos archivos que pretenden brindar un mayor bagaje histórico, y que lo logran aunque sin dejar de lado sus reconfiguraciones, construyen una figura que viene también a poner en evidencia los contextos históricos de los propios documentales. Pereira, Envar el Kadri, nutren la figura a partir de impartir a Gerardo Klein la falta de conocimiento, un termómetro de la época. Bauer se une a la propuesta del revisionismo histórico y entonces conforma un mundo libertario alrededor de la figura de Guevara, uniéndolo a la idea de la unidad latinoamericana.

En este sentido, la construcción de la memoria se vuelve dinámica en tanto que la práctica documental es de por sí un fenómeno complejo compuesto por el relato memorial que realizan los creadores y difunden hacia un abanico amplio de espectadores. Un abanico amplio en tanto que abarcan generaciones e ideologías diversas. A su vez, los creadores reinterpretan archivos que no siempre provienen de un pensamiento afín, y entonces lo resignifican. También imprimen su mirada sobre los testimonios, y la afección de los sujetos que testimonian, en este caso sobre la figura del Che y sus discursos políticos.

En este punto el primer documental deja la figura en sus mitos y observa las repercusiones populares que obtuvo en los pueblos por los que pasó. En algún 
punto persiste la imagen de héroe guerrillero y se le suma la de mártir y santo. El segundo documental baja el nivel de santidad y postura monumental sobre la figura agregando materiales de la vida privada y mostrando los archivos propios de Guevara, sin embargo, el balance de qué período de la vida se narra lo vuelve a ubicar en el podio. Empero, por el manejo de las imágenes y sobre todo por el tipo de planteo político mientras que el primer documental construye un líder popular, el segundo explica porque surgió ese líder y realiza una apertura de las luchas armadas al pueblo.

De todos modos, ambos documentales barajan la opción de llevar a escena los pueblos tercermundistas como pueblos que como vimos permanecen en un devenir social. En este sentido vemos que con el revisionismo histórico y en el caso latinoamericano, a pesar de haber padecido genocidios, no se cercenó la necesidad de representar los pueblos latinoamericanos. En este caso, se los construyó mediante imágenes propias de los pueblos de hoy y de ayer y los discursos políticos de la figura que se proponen representar los documentales. Queda abierta la pregunta si esa diferencia con los pueblos europeos de posguerra se debe a la idiosincrasia y/o al resurgimiento de los gobiernos progresistas en la región.

\section{Referencias bibliográficas}

Amado, A. (2009). La imagen justa. Cine argentino y política (1980-2007). Buenos Aires: Colihue.

Aprea, G. (2015). Documental, testimonios y memorias. Miradas sobre el pasado militante. Buenos Aires: Manantial.

Barthes, R. (2004). Mitologías. Buenos Aires: Siglo veintiuno.

Cattaruzza, A. (2007). Los usos del pasado. La historia y la política argentinas en discusión, 1910-1945. Buenos Aires: Sudamericana.

Ciancio, M. B. (2015). Laberintos y líneas de memoria en el documental argentino contemporáneo. In A. Traverso \& T. Crowder-Taraborrelli. (eds.) El documental político en Argentina, Chile y Uruguay: de los años cincuenta a la década del dos mil (pp.83-101). Santiago de Chile: LOM.

Geltman, P. (1969). Los mitos. Buenos Aires: Carlos Pérez Editor.

Gilio, M. (1999). Estoy condenado a hacer un cine marginal. Página 12, 04/01/1999. Disponible en www.pagina12.com.ar/1999/99-01/99-01-04/ pag12.htm

Hobsbawm, E. (2011). Cómo cambiar el mundo. Marx y el marxismo 18402011. Buenos Aires: Crítica. 
Lanza, P. (2016). Héroes y traidores: sobre los documentales de la militancia revolucionaria argentina. Revista Imagofagia, (14). Disponible en www.asaeca.org/imagofagia

Lindeperg, S. (2009). Noche y niebla un film en la historia. Cuadernos de cine documental, (03): 58-73. Santa Fe: UNL.

O'Donnell, M. (2012). Che. El argentino que quiso cambiar el mundo. Buenos Aires: Sudamericana.

Sánchez, G. (1989). Che: su otra imagen. In Centro de Estudios de América. Pensar al Che (pp. 1078-108). Havana: Editorial José Martí.

Sobchack, V. (2011). Hacia una fenomenología de la experiencia no-ficcional (Tr. S. Pardo). Revista On-Line Cine Documental, (4). Disponible en www.revista.cinedocumental.com.ar

Tablada Pérez, C. (1987). El pensamiento económico de Ernesto Che Guevara. Casa de las Américas, Julio- Agosto XXVIII, 163.

\section{Filmografía}

Che un hombre nuevo (2010), de Tristan Bauer.

Che... Ernesto (1997), de Miguel Pereira. 